\title{
Simulating the Poverty Impact of Macroeconomic Shocks and Policies
}

\author{
B. Essama-Nssah* \\ Poverty Reduction Group \\ (PRMPR) \\ The World Bank \\ Washington, D.C.
}

\begin{abstract}
Developing countries face a host of macroeconomic challenges in the design and implementation of development strategies and policies. The importance of the underlying poverty and distributional issues creates a need for relevant and reliable ways of tracking the social impact of shocks and policies. This paper describes, and demonstrates the use of, a stylized framework for simulating the poverty implications of the Dutch disease, a change in the terms of trade and budgetary policy. The basic approach is to embed a Lorenz model of the size distribution of economic welfare in a general equilibrium model of an open economy. It is observed that, while aggregate welfare and poverty effects may be negligible, the structural and distributional impacts tend to be significant. The latter drive the political economy of policy-making, and point to the need for an analytical framework that accounts for both the structural richness of the economy and the heterogeneity of the stakeholders.
\end{abstract}

\section{World Bank Policy Research Working Paper 3788, December 2005}

The Policy Research Working Paper Series disseminates the findings of work in progress to encourage the exchange of ideas about development issues. An objective of the series is to get the findings out quickly, even if the presentations are less than fully polished. The papers carry the names of the authors and should be cited accordingly. The findings, interpretations, and conclusions expressed in this paper are entirely those of the authors. They do not necessarily represent the view of the World Bank, its Executive Directors, or the countries they represent. Policy Research Working Papers are available online at http://econ.worldbank.org.

\footnotetext{
* The author is grateful to Delfin Sia Go and an anonymous referee for their insightful comments.
} 


\section{Introduction}

In the context of the Millennium Declaration (United Nations 2000), the international community has included poverty and hunger eradication among the basic objectives of development. This makes poverty reduction a benchmark measure of the performance of socioeconomic systems. Furthermore, distributional issues underpin socioeconomic outcomes of policymaking because of the heterogeneity of the interests involved. Developing countries face a host of macroeconomic challenges in the design and implementation of development strategies and policies. In fact, macroeconomic stability is now considered a key determinant of sustainable economic growth and development. The importance of poverty and distributional issues in policymaking therefore creates a need for ways of assessing the social impact of shocks and policies.

In the case of an oil-importing country, for instance, the macroeconomic effects of an event such as an oil price increase may indeed include changes in a number of flowof-funds variables that determine macroeconomic equilibrium. The deficit in the balance of payments account and in the public budget may worsen, with implications for the supply of money. Also, aggregate income and absorption may fall while the general price level increases (Robinson and Tyson 1984, Cooper 1992).

The policy response to these types of shocks is a function of the nature and the size of the macroeconomic imbalances created by the shock, as well as its welfare and structural implications. Indeed, macroeconomic shocks are bound to have structural and distributional implications that work through individual markets and supporting institutions. For instance, an increase in the relative price of oil will have substitution effects for both final and intermediate consumption. This situation creates interdependence between stabilization, structural and distributional issues arising from macroeconomic shocks and policies (Robinson and Tyson 1984). In addition, there is interdependence among policy instruments that a government may use in order to restore internal and external balance. It is well-known that exchange rates, tariffs, subsidies and trade liberalization have implications for fiscal policy. In addition there is interaction between fiscal and monetary policies (Blejer and Chu 1989).

The formulation of relevant and reliable policy recommendations requires a modeling framework that can handle both aggregate economic performance and the 
structural and distributional implications of economic shocks and policies. In particular, the framework should account for interdependence between policy issues and instruments, and for the distribution of economic welfare among socioeconomic groups, households and individuals. A general equilibrium framework offers an attractive point of departure because it has both macro and micro elements upon which to base the analysis of some macroeconomic shocks and policies.

A general equilibrium analysis of the distributional implications of macroeconomic shocks and policies may follow three basic approaches: (1) the standard representative household ( $\mathrm{RH})$ approach, (2) the extended representative household approach (ERH), and (3) the microsimulation approach. The standard RH approach limits the analysis of the distributional impact of shocks and policies to their effects on the mean welfare within a few representative socioeconomic groups. In this framework, one can predict the impact of shocks and policies on the functional distribution and on between-group inequality but not on poverty. Poverty analysis requires the specification of the size distribution within groups. One way of extending the RH is to model withingroup size distribution with a density function associated with a well-known distribution such as the lognormal or the beta (Dervis, de Melo and Robinson 1982; Decaluwé, Patry, Savard and Thorbecke 1999). Another way is to use unit record data drawn directly from a household survey to represent the size distribution of economic welfare. This is consistent with the microsimulation approach (Ravallion and Lokshin 2004, Bourguignon, Robilliard and Robinson 2003).

This paper focuses on the ERH approach. However, instead of relying on a parametric distribution, it demonstrates how the Lorenz curve can help link an extended functional distribution to a size distribution of economic welfare to analyze the poverty impact of macroeconomic events. Indeed, the Lorenz curve provides an integrative framework for both the simulation and ethical evaluation of inequality and poverty. Most, if not all, inequality and poverty measures of interest can be computed from the level of income or expenditure $\mathbf{x}$, the associated density function $\mathbf{f}(\mathbf{x})$, and a poverty line (for poverty measures). We can recover both the level of income and the density function from a parameterized Lorenz function and the mean of the distribution. This information is all we need for the computation of the relevant indicators. There are examples from 
the literature (Ravallion and Datt 1992; Datt 1992, 1998) of the use of the Lorenz curve to simulate the poverty implications of macroeconomic events based on their assumed impact on the mean of the distribution. In most cases, the macroeconomic model remains implicit. We therefore extend this approach by embedding it in a general equilibrium model.

The outline of the paper is as follows. Section 2 describes the simulation framework. The general equilibrium model is adapted from a stylized one developed by Devarajan, Lewis and Robinson (1990). The size distribution of economic welfare is derived from a parameterization of the General Quadratic Lorenz curve (Datt 1992, 1998). Section 3 presents an application of the framework to study the poverty implications of three categories of macroeconomic shocks and policies: (1) Dutch disease; (2) changes in the terms of trade; and (3) budgetary policy. Concluding remarks are made in section 4 .

\section{The Simulation Framework}

This section focuses on the structure and the numerical implementation of the simulation framework. We start from the simple observation that poverty and inequality measures are computed on the basis of a distribution of an indicator of economic welfare, say income. Such a distribution is fully characterized by its mean and the relative inequality. Thus the poverty and distributional impact of a macroeconomic shock or policy can be analyzed in terms of change in the mean and changes in relative inequality. This suggests a two-dimensional framework whereby a general equilibrium model is used to track the impact on the mean, and changes in the mean are combined with a Lorenz function to predict the poverty impact.

\subsection{A Two-Sector Model of an Open Economy}

The stylized general equilibrium model we use here was developed by Devarajan, Lewis and Robinson (1990) to study the efficiency implications of commodity taxation. It is an extension of the Generalized Salter-Swan model of international trade couched 
within the logic the Walrasian framework ${ }^{1}$. There are two sectors of production: one producing an export good (not sold domestically), and the other a domestic good that is used for both intermediate and final consumption. The demand for primary factors of production (capital and labor) is a consequence of profit maximization by firms in each sector. There is a distinction between imported intermediate and final goods. The domestic good is an imperfect substitute for imports. The government has available three tax instruments: tariffs on final and intermediate goods and an indirect tax on domestic sales.

The original version of the model has only one representative consumer who owns all factors of production, receives all tax revenue from the government in a lump sum. The consumer spends her income so as to maximize utility. Given our interest in distributional issues and for the sake of simplicity, we introduce two representative households, one rural and the other urban. We now consider a more explicit expression of the model.

\section{Production and Employment of Factors of Production}

Assuming constant returns to scale, the production functions in each sector are described by the following Cobb-Douglas expressions ${ }^{2}$ :

$$
X_{i}=A_{i} K_{i}^{\alpha_{k i}} L_{i}^{\alpha_{l i}} ; \quad \alpha_{k i}+\alpha_{l i}=1 ; \quad i=e, d .
$$

where $\mathrm{K}_{\mathrm{i}}$ and $\mathrm{L}_{\mathrm{i}}$ stand respectively for capital and labor employed in sector $\mathbf{i}$ (e stands for export sector and $\mathbf{d}$ for domestic good). Let $\mathbf{w}$ stand for the wage rate and $\mathrm{PVA}_{\mathrm{i}}$ for the

\footnotetext{
${ }^{1}$ Bénassy (2002) characterizes the Walrasian paradigm as follows. All agents receive the same price signal from a mechanism controlled by an implicit auctioneer. In response, each agent sends to the markets his or her demands and supplies, outcomes of optimizing behavior. Equilibrium prices emerge from the equality of aggregate demand and supply in all markets. No agent experiences any quantity constraint. This author also notes the following missing links in the Walrasian model. All agents receive price signals, but none sends out any. All agents send quantity signals to the markets, but no one makes any use of information about quantities available on the market.

${ }^{2}$ It is possible to model technology through a constant elasticity of transformation (CET) function representing the production possibility frontier between exports and domestic goods. Devarajan, Lewis and Robinson (1990) explain that, when sectoral production functions are Cobb-Douglas, the corresponding transformation function is approximately a CET function.
} 
value-added per unit output in sector $\mathbf{i}$, then the demand for labor can be derived from the first order conditions for profit maximization ${ }^{3}$. The corresponding equations are:

$$
L_{i}=\frac{\alpha_{l i}\left(P V A_{i} X_{i}\right)}{w} ; \quad i=e, d .
$$

Similarly, letting $\mathbf{r}$ stand for the return to capital in sector $\mathbf{i}$, the demand for capital is given by:

$$
K_{i}=\frac{\alpha_{k i}\left(P V A_{i} X_{i}\right)}{r} ; \quad i=e, d
$$

Let $\mathbf{P} \mathbf{X}_{\mathbf{i}}$ and $\mathbf{P} \mathbf{Q}_{\mathbf{j}}$ stand respectively for the producer price in sector $\mathbf{i}$ and the user price for commodity $\mathbf{j}$ ( $\mathrm{j}=1$ for final and 2 for intermediate consumption). If $\mathbf{a}_{2 \mathbf{i}}$ represents the amount of intermediate good per unit of output in sector $\mathbf{i}$, then the net price in sector $\mathbf{i}$ is given by the following equation.

$$
P V A_{i}=P X_{i}-a_{2 i} P Q_{2}, \quad i=e, d
$$

The producer price for exports $\mathbf{P X}_{\mathbf{e}}$ is a function of the exchange rate $\mathbf{R}$, the world price $\pi_{\mathbf{e}}$ and any applicable subsidy or tax.

$$
P X_{e}=R\left(1+t_{e}\right) \pi_{e}
$$

\section{Consumption Possibilities}

There are two commodities available for both final $(j=1)$ and intermediate $(j=2)$ consumption. Each is assumed to be CES aggregation of imports $\mathbf{M}_{\mathbf{j}}$ and domestic goods $\mathbf{D}_{\mathbf{j}}$. The elasticity of substitution is defined as: $\sigma_{j}=\frac{1}{1+\rho_{j}}, j=1,2$. The aggregation follows the Armington specification:

$$
Q_{j}^{s}=B_{j}\left[\beta_{j} M_{j}^{-\rho_{j}}+\left(1-\beta_{j}\right) D_{j}^{-\rho_{j}}\right]^{-\frac{1}{\rho_{j}}} ; \quad j=1,2
$$

The corresponding imports demands functions are:

$$
M_{j}=B_{j}^{-1}\left[\beta_{j}^{\sigma_{j}} P M_{j}^{\left(1-\sigma_{j}\right)}+\left(1-\beta_{j}\right)^{\sigma_{j}} P D_{j}^{\left(1-\sigma_{j}\right)}\right] \frac{1}{\left(1-\sigma_{j}\right)} \beta_{j}^{\sigma_{j}} P M_{j}^{-\sigma_{j}} Q_{j}^{s} ; j=1,2
$$

\footnotetext{
${ }^{3}$ One could also invoke cost minimization to derive the following factor demand functions: $L_{i}=\left(\frac{\alpha_{l i}}{\alpha_{k i}} \frac{r}{w}\right)^{\alpha_{k i}}\left(X_{i} / A_{i}\right) ; i=e, d$ and $K_{i}=\left(\frac{\alpha_{k i}}{\alpha_{l i}} \frac{w}{r}\right)^{\alpha_{l i}}\left(X_{i} / A_{i}\right) ; i=e, d$.
} 
Similarly, the demand for the domestic component is given by:

$$
D_{j}=B_{j}^{-1}\left[\beta_{j}^{\sigma_{j}} P M_{j}^{\left(1-\sigma_{j}\right)}+\left(1-\beta_{j}\right)^{\sigma_{j}} P D_{j}^{\left(1-\sigma_{j}\right)}\right]^{\frac{1}{\left(1-\sigma_{j}\right)}}\left(1-\beta_{j}\right)^{\sigma_{j}} P D_{j}^{-\sigma_{j}} Q_{j}^{s} ; j=1,2
$$

The domestic price for imports is given by the following expression.

$$
P M_{j}=R\left(1+t m_{j}\right) \pi_{j}^{m} ; j=1,2
$$

where $\mathbf{t m}_{\mathbf{j}}$ is the applicable tariff rate and $\pi_{j}^{m}$ is the relevant world price of imports.

The sales price of the domestic good includes a sales tax at a rate $\mathbf{t x}_{\mathbf{d}}$, and can be computed as follows:

$$
P D_{j}=P X_{d}\left(1+t x_{d}\right) ; \quad j=1,2
$$

where $\mathbf{P X}_{\mathbf{d}}$ stands for the producer price in the domestic good sector and is equal to:

$$
P X_{d}=\frac{\sum_{j=1}^{2} P D_{j} D_{j}}{X_{d}\left(1+t x_{d}\right)} ; j=1,2
$$

The prices of composite goods are computed as follows.

$$
P Q_{j}=\left(P D_{j} D_{j}+P M_{j} M_{j}\right) / Q_{j}^{s} ; j=1,2
$$

The income of the representative household for each socioeconomic group, $\mathbf{Y}_{\mathbf{h}}$, includes a fraction of all labor and capital income (hence a fraction of total value-added), a share of the balance of trade in local currency and a lump sum transfer of part of government revenue $\mathbf{Y}_{\mathbf{G}}$ (from taxes). Thus we have:

$$
Y_{h}=\theta_{h l}(w L S)+\theta_{h k}(r K S)+\theta_{h g} Y_{G}+\theta_{h f} R S_{f} ; \quad h=r, u
$$

The parameter $\boldsymbol{\theta}_{\mathbf{h s}}$ is the share of income of household $\mathbf{h}$ derived from source $\mathbf{s}$. Government revenue is given by:

$$
Y_{G}=\sum_{j=1}^{2} t m_{j}\left(R \pi_{j}^{m} M_{j}\right)+t x_{d} X_{d}
$$

All private income is spent on the final good according to the following demand equations:

$$
Q_{1 h}^{d}=\frac{Y_{h}}{P Q_{1}} ; \quad h=r, u ; \quad Q_{1}^{d}=\sum_{h} Q_{1 h}^{d}
$$

Total demand for the intermediate good is given by the following expression: 


$$
Q_{2}^{d}=\sum_{i} a_{2 i} X_{i} ; \quad i=e, d
$$

\section{Equilibrium Conditions}

Finally, the following conditions must hold at equilibrium. Supply equals demand for the home good.

$$
X_{d}=\sum_{j=1}^{2} D_{j} ; j=1,2
$$

There is material balance for the composite goods:

$$
Q_{j}^{s}=Q_{j}^{d} ; j=1,2
$$

Supply equals demand on all factor markets.

$$
L S=\sum_{i} L_{i} ; \quad K S=\sum_{i} K_{i} ; \quad i=e, d
$$

where $\mathbf{L S}$ and $\mathbf{K S}$ stand respectively for total labor supply and total capital stock. The government balances its budget, and the trade balance is written as follows.

$$
\pi_{e} X_{e}+S_{f}=\sum_{j=1}^{2} \pi_{j}^{m} M_{j}
$$

The consideration of the poverty implications of macroeconomic events within a general equilibrium model depends on the way such a model captures the effects of shocks and policies on macro balances and the transmission of the repercussions to households (Robinson and Löfgren 2005). A standard general equilibrium model of an open economy usually includes three macro balances related to the government account, the rest of the world and the equilibrium between savings and investment. The specification of how balance is achieved in each of these three macro accounts is known as macro closure, and determines the macroeconomic adjustment to shocks.

In the simplified framework considered here, there is an equation for government revenue from taxes (2.14), but no explicit equation for the government budget. This is due to the fact that the government redistributes all its revenue to the households. There is a balance of trade equation showing foreign savings assumed exogenous. In a standard 
model, these foreign savings are usually added to household and government savings in order to finance real investments. This is not the case in this simplified framework where no domestic agent saves anything (see equation 2.15 showing that each consumer exhausts her income on the final good). The lack of investment in this simple framework means that foreign savings are distributed to households as described by equation (2.13). Hence, the macro story is essentially driven by aggregate demand that will adjust to any shock through household expenditures.

\subsection{The Lorenz Model of the Size Distribution of Income}

The information content of a cumulative distribution function (CDF) can be transformed into a Lorenz curve. Assume that all individuals are ranked in ascending order of the welfare indicator. Let $\mathbf{p}$ stand for the poorest $100 \mathbf{p}$ percent of the population, and $\mathbf{L}(\mathbf{p})$, the share of total welfare going to this segment of the population. The Lorenz curve maps the cumulative proportion $\mathbf{p}$ of the population on the horizontal axis (starting from the poorest) against the cumulative share of welfare $\mathbf{L}(\mathbf{p})$ on the vertical axis.

To make matters simple, we take the underlying density function to be smooth. The distribution function associated with such a smooth density is defined by the following expression:

$$
F(x)=\int_{0}^{x} f(t) d t ; \quad F^{\prime}(x)=f(x)
$$

Thus the density function is the first order derivative of the distribution function. In this case, the Lorenz curve is defined by the following (Lambert 2001):

$$
p=F(x) \Rightarrow L(p)=\int_{0}^{x} \frac{t f(t) d t}{\mu}
$$

The definition of the distribution function given by (2.21) implies that $\mathbf{d p}=\mathbf{f}(\mathbf{x}) \mathbf{d x}$. Therefore, the Lorenz function may also be written as:

$$
L(p)=\int_{0}^{p} \frac{x(q)}{\mu} d q
$$

Differentiating with respect to $\mathbf{p}$, we find that the first order derivative is equal to:

$$
L^{\prime}(p)=\frac{x(p)}{\mu}
$$


The second order derivative is equal to:

$$
L^{\prime \prime}(p)=\frac{1}{\mu} \frac{d x}{d p}=\frac{1}{\mu \frac{d p}{d x}}=\frac{1}{\mu f(x)}
$$

Given an analytical expression for the Lorenz curve and the mean of the corresponding distribution, we can use expressions (2.24) and (2.25) for the first and second order derivatives of the Lorenz curve to recover the level of economic welfare at percentile $\mathbf{p}$, and the associated density. Furthermore $\mathbf{f}(\mathbf{x}) \mathbf{d} \mathbf{x}$ is interpreted as the proportion of people whose level of welfare lies in the close interval $[\mathbf{x}, \mathbf{d x}]$ for a given $\mathbf{x}$ and an infinitesimal change $\mathbf{d x}$ (Lambert 2001). This is the bedrock of our simulation approach. This is indeed the only information we need to recover all desired measures of poverty and inequality. For instance, members of the Foster-Greer-Thorbecke family of poverty measures can be computed as:

$$
P_{\alpha}=\sum_{h=1}^{m} \max \left[\left(1-\frac{\mu}{z} \frac{\Delta L\left(p_{h}\right)}{\Delta p_{h}}\right)^{\alpha}, \quad 0\right] f\left(x_{h}\right) \Delta x_{h}
$$

In the above expression, $\mathbf{z}$ stands for the poverty line.

Our simulations are based on the Quadratic Lorenz curve which is defined by the following expression (Datt 1992, 1998):

$$
L(p)=-\frac{1}{2}\left[\beta_{2} p+e+\left(m p^{2}+n p+e^{2}\right)^{\frac{1}{2}}\right]
$$

The corresponding first order derivative is equal to:

$$
L^{\prime}(p)=-\frac{\beta_{2}}{2}-\frac{2 m p+n}{4 \sqrt{\left(m p^{2}+n p+e^{2}\right)}}
$$

The second order derivative is:

$$
L^{\prime \prime}(p)=\frac{r^{2}\left(m p^{2}+n p+e^{2}\right)^{-\frac{3}{2}}}{8}
$$

\subsection{Numerical Implementation}

Numerical implementation entails fitting the above described analytical structure to a data set representing the state of the economy for a given period. Usually, it is 
believed that the data set represents base year equilibrium. The resulting empirical model may then be used to conduct counterfactual simulations in order to examine the likely change in equilibrium values of endogenous variables induced by changes in some exogenous variables. We briefly describe the calibration of the general equilibrium model and the estimation of the parameters characterizing the general quadratic Lorenz curve.

\section{Calibration of the General Equilibrium Model}

The necessary data for an empirical economy-wide model must be organized in a frame that reflects the circular flow of economic activity for the chosen year. The Social Accounting Matrix (SAM) offers such a framework. It provides an analytically integrated data set which reflects various aspects of the economy such as production, consumption, trade, accumulation and income distribution. A SAM is a square matrix, the dimension of which is determined by the chosen degree of disaggregation which itself is constrained by the issues of concern and data availability. Each account is represented by a combination of one row and one column with the same label. Each entry represents a payment to a row account by a column account. Thus, all receipts into an account are read along the corresponding row while payments by the same account are recorded in the corresponding column. In accordance to the principles of double-entry bookkeeping, the whole construct is subject to a consistency restriction which makes the column sums equal to the corresponding row sums. This restriction also means that the SAM obeys Walras' Law in the sense that, for an $\mathbf{n}$-dimensional matrix, if the (n-1) accounts balance, so must the last one. Table 2.1 shows the structure of the SAM underlying the basic model described above. The government account is not included because all taxes and transfers are assumed to be zero in the base year ${ }^{4}$.

\footnotetext{
${ }^{4}$ This base case was chosen by the authors because they were also interested in finding the optimal configuration of the tax instruments. Such a configuration would not distort private sector decisions.
} 
Table 2.1. Base Year SAM for the Two-Sector Model

\begin{tabular}{|c|c|c|c|c|c|c|c|c|c|c|}
\hline & Export I & omestic & Final & Intermediate & Labor & Capital & Rural & Urban & World & Total \\
\hline Export & & & & & & & & & 30.00 & 30.00 \\
\hline Domestic & & & 73.00 & 2.00 & & & & & & 75.00 \\
\hline Final & & & & & & & 40.00 & 60.00 & & 100.00 \\
\hline Intermediate & 5.00 & & & & & & & & & 5.00 \\
\hline Labor & 20.00 & 30.00 & & & & & & & & 50.00 \\
\hline Capital & 5.00 & 45.00 & & & & & & & & 50.00 \\
\hline Rural Household & & & & & 35.00 & 5.00 & & & & 40.00 \\
\hline Urban Household & & & & & 15.00 & 45.00 & & & & 60.00 \\
\hline World & & & 27.00 & 3.00 & & & & & & 30.00 \\
\hline Total & 30.00 & 75.00 & 100.00 & 5.00 & 50.00 & 50.00 & 40.00 & 60.00 & 30.00 & \\
\hline
\end{tabular}

Source: Adapted from Devarajan, Lewis and Robinson (1990)

To make the general equilibrium model fully computable, we must find numerical estimates for the structural parameters characterizing technology, the distribution of income among households and import aggregation functions. When these parameters cannot be estimated econometrically, one can resort to model calibration. This process solves relevant equations for values of the parameters that are consistent with base year data. For the parameters of the Cobb-Douglas production functions we have the following expressions:

$$
\alpha_{l i}=\frac{w L_{i}}{\left(P V A_{i}\right) X_{i}} ; \alpha_{k i}=\left(1-\alpha_{l i}\right) ; \quad A_{i}=\frac{X_{i}}{K_{i}^{\alpha_{k i}} L_{i}^{\alpha_{l i}}} \quad i=e, d .
$$

The parameters of the Armington function are given by the following:

$$
\beta_{j}=\frac{1}{1+\frac{P D_{j}}{P M_{j}}\left(\frac{Q_{j}^{s}}{D_{j}}\right)^{-\frac{1}{\sigma_{j}}}} ; \quad B_{j}=\frac{Q_{j}^{s}}{\left[\beta_{j} M_{j}^{-\rho_{j}}+\left(1-\beta_{j}\right) D_{j}^{-\rho_{j}}\right]^{-\frac{1}{\rho_{j}}}} ; j=1,2 .
$$

Where: $\rho_{j}=\frac{1-\sigma_{j}}{\sigma_{j}}$.

Based on the above expression and the base data presented in SAM (table 2.1) the calibration process led to the results presented in table 2.2. This information reveals that the export sector is labor intensive relative to the domestic sector. The latter is more capital intensive than the former. Thus this stylized model may be thought of as representing a developing country exporting a primary agricultural commodity produced 
by smallholders using low-tech methods of production. The domestic sector produces an import competing good with capital intensive methods. The elasticity of substitution between imports and the domestic good is assumed to be 0.5 for the intermediate good and 2.0 for the final good.

Table 2.2 Calibrated Parameters for the Two-Sector Model

\begin{tabular}{lcccccc}
\hline & $\alpha_{\mathrm{l}}$ & $\alpha_{\mathrm{k}}$ & $\mathrm{A}$ & $\beta_{\mathrm{M}}$ & $\beta_{\mathrm{D}}$ & $\mathrm{B}$ \\
\hline Export & 0.80 & 0.20 & 1.98 & & & \\
Domestic & 0.40 & 0.60 & 1.98 & & & \\
Final & & & & 0.38 & 0.62 & 1.89 \\
Intermediate & & & & 0.69 & 0.31 & 1.92 \\
\hline
\end{tabular}

Source: Author's calculations

As far as the functional distribution of income is concerned, it is assumed that the rural household owns 70 percent of labor and 10 percent of capital. Therefore the urban household owns 30 percent of labor and 90 percent of capital. Furthermore, when we introduce the government, we assume that the rural population gets 60 percent of transfers from the public budget. The urban households receive 40 percent. In this simple framework, the role of the government is solely to redistribute its revenue from taxes to households. Finally, we make the assumption that rural households receive 20 percent of the trade balance and the urban folks 80 percent. In the base case, the balance of trade is equal to zero.

\section{Lorenz Parameter Estimation}

When household data are available, either in the form of unit records or aggregated in income or expenditure classes, one can use regression analysis to fit the data to a model such as the General Quadratic model. We follow the procedure described in Datt(1992, 1998). This calls for regressing [L(1-L)] on $\left(\mathbf{p}^{\mathbf{2}} \mathbf{- L}\right), \mathbf{L}(\mathbf{p}-\mathbf{1})$ and $(\mathbf{p}-\mathbf{L})$ without an intercept, and dropping the last observation since the chosen functional form forces the curve to go through $(1,1)$. Here $\mathbf{p}$ stands for the abscissa (horizontal coordinate) while $\mathbf{L}$ stands for the ordinate of the Lorenz curve estimated from the initial 
data. Let $\beta_{1}, \beta_{2}$, and $\beta_{3}$ be the regression coefficients. The following parameters characterize the general quadratic Lorenz function.

$$
e=-\left(\beta_{1}+\beta_{2}+\beta_{1}+1\right) ; m=\left(\beta_{2}^{2}-4 \beta_{1}\right) ; n=\left(2 \beta_{2} e-4 \beta_{3}\right) ; r=\left(n^{2}-4 m e^{2}\right)^{\frac{1}{2}}
$$

Table 2.3 Size Distribution of Income within the Socioeconomic Groups in the SAM

\begin{tabular}{lccccccccccc}
\hline Group & Mean & $\begin{array}{c}\text { Poorest } \\
\text { Decile }\end{array}$ & 2nd & 3rd & 4th & 5th & 6th & 7th & 8th & 9th & 10th \\
\cline { 4 - 4 } & 0.01 & 0.03 & 0.04 & 0.06 & 0.07 & 0.09 & 0.11 & 0.14 & 0.18 & 0.28 \\
National & 1.00 & 0.02 & 0.03 & 0.05 & 0.07 & 0.08 & 0.10 & 0.12 & 0.14 & 0.17 & 0.21 \\
Rural & 0.66 & 0.00 & 0.04 & 0.06 & 0.07 & 0.09 & 0.10 & 0.12 & 0.14 & 0.16 & 0.23 \\
Urban & 1.50 & 0.00 &
\end{tabular}

Source: Author's calculations

The unit record data underlying table 2.3 were generated randomly from the beta distribution. The probability density function is defined by the following expression (Johnson, Kotz and Balakrishnan 1995):

$$
f(y)=\frac{1}{B(q, r)} \frac{(y-a)^{q-1}(b-y)^{r-1}}{(b-a)^{q+r-1}}, \quad a \leq y \leq b
$$

where $\mathrm{B}(\mathrm{q}, \mathrm{r})$ stands for the beta integral (also known as the Euler integral of the second kind) defined as:

$$
B(q, r)=\int_{0}^{1} t^{q-1}(1-t)^{r-1} d t, \quad q, r>0
$$

Setting $x=(y-a) /(b-a)$ leads to the following standard form of the beta density function:

$$
f(x)=\frac{1}{B(q, r)} x^{q-1}(1-x)^{r-1}, \quad 0 \leq x \leq 1
$$

The corresponding probability integral up to $\mathbf{x}$ is given by the incomplete beta ratio or incomplete beta integral: 


$$
I(x ; q, r)=\frac{1}{B(q, r)} \int_{0}^{x} t^{q-1}(1-t)^{r-1} d t
$$

The national (or overall) distribution is a combination of 60 observations representing the rural population and 40 observations representing the urban population. Rural observations are drawn from a distribution with parameters $(1.3,4.0)$ while the urban observations are drawn from a distribution characterized by these parameters (1.2, 3.5).

Table 2.4 Baseline Inequality

\begin{tabular}{cccc}
\hline Focus & National & Rural & Urban \\
\hline 1 & 0.00 & 0.00 & 0.00 \\
2 & 0.41 & 0.32 & 0.32 \\
3 & 0.57 & 0.47 & 0.47 \\
4 & 0.65 & 0.56 & 0.57 \\
5 & 0.71 & 0.62 & 0.64 \\
6 & 0.74 & 0.66 & 0.69 \\
\hline
\end{tabular}

Source: Author's calculations

Table 2.4 shows baseline inequality in the distribution of income in terms of the extended Gini Coefficient. This measure of inequality is analogous to the Atkinson index of inequality to the extent that it depends on a focal parameter which is interpreted as an indicator of social aversion to inequality. When this aversion parameter is equal to 2, the extended Gini is equal to the ordinary Gini coefficient. According to table 2.4, the Gini coefficient is equal to 41 percent for the global distribution and to about 32 percent in both the rural and the urban areas. 
Table 2.5 Estimated Parameters of the Underlying Lorenz Function

\begin{tabular}{lccc}
\hline Parameter & National & Rural & Urban \\
\hline$\beta_{1}$ & 1.52 & 2.16 & 1.46 \\
$\beta_{2}$ & -0.89 & -1.42 & -1.83 \\
$\beta_{3}$ & 0.02 & 0.08 & -0.15 \\
$\mathrm{e}$ & -1.65 & -1.82 & -0.48 \\
$\mathrm{~m}$ & -5.29 & -6.60 & -2.51 \\
$\mathrm{n}$ & 2.86 & 4.84 & 2.37 \\
$\mathrm{r}$ & 8.11 & 10.50 & 2.82 \\
\hline
\end{tabular}

Source: Author's calculations

\section{The Poverty Impact of Macroeconomic Shocks and Policies}

We use the above simulation framework to analyze the poverty implications of some macroeconomic events. We consider first two types of exogenous shocks, an increase in foreign transfers and a deterioration of the terms of trade. Finally we analyze the case of budgetary policy.

\subsection{Exogenous Shocks}

Table 3.1 Structural and Poverty Implications of Exogenous Shocks ${ }^{5}$

\begin{tabular}{lccc}
\hline & Base & Dutch & Deterioration TOT \\
\hline Exports & 30.0 & 78.63 & 94.50 \\
Domestic Good & 75.0 & 106.98 & 101.83 \\
Final Imports & 27.0 & 115.59 & 85.89 \\
Intermediate Imports & 3.0 & 79.19 & 94.67 \\
Total Consumption & 100.0 & 109.87 & 97.54 \\
Rural Consumption & 40.0 & 101.50 & 96.63 \\
Urban consumption & 60.0 & 115.48 & 98.15 \\
Total Poverty Incidence & 59.2 & 96.61 & 103.39 \\
Rural Poverty Incidence & 78.3 & 98.72 & 102.56 \\
Urban Poverty Incidence & 30.5 & 83.33 & 103.33 \\
Overall Poverty Gap & 29.7 & 96.67 & 103.33 \\
Rural Poverty Gap & 38.7 & 97.44 & 102.56 \\
Urban Poverty Gap & 16.3 & 87.50 & 106.25 \\
\hline
\end{tabular}

Source: Author's calculations

\footnotetext{
${ }^{5}$ Except for the base case, results are reported in percentage of base case values
} 
Table 3.1 presents the results for two simulations. The column labeled "Dutch" reports the results of an increase in foreign transfers from 0 to 10. The last column of the table shows the consequences of 10 percent increase in the world price of final imports, a deterioration of the terms of trade. As noted above, baseline results are in levels while all other results are reported in percentage of the base case values. We comment on these results below.

\section{Dutch Disease}

The term "Dutch disease" refers to the decline of the Netherlands' export competitiveness in the 1970's following the discovery and exploitation of the Groningen natural gas fields (Benjamin and Devarajan 1985, Benjamin, Devarajan and Weiner 1989). In general, the Dutch disease effect is the adverse effect that real appreciation of the exchange rate has on the tradable sectors of the economy as a result of an increase in foreign capital inflow (Corden 2002).

When an economy undergoes a shock (be it an exogenous or a policy shock), its structure may change significantly and such a change is likely to have significant structural and distributional implications. According to the results presented in table 3.1 above, an increase in foreign transfers (which is equivalent to 10 percent of base year GDP) causes a structural adjustment of the economy that is consistent with the Dutch disease. There is a marked decline of the export sector where production falls by about 21 percent, while the production of the domestic good increases by about 7 percent. This phenomenon is understood as follows. The increase in foreign capital inflow is distributed to households. This increase in income leads to an increase in the demand for both the domestic good and imports (due to the assumption of imperfect substitutability between homemade goods and imports). The increased demand for the non-tradable good induces an increase in its price relative to that of exports, hence a real appreciation of the exchange rate ${ }^{6}$. This appreciation of the exchange rate causes resources to move out of the export sector to the non-tradable sector to meet the increase demand for the

\footnotetext{
${ }^{6}$ The exchange rate is the numéraire price in this model and the small country assumption implies that the world price of exports is fixed as well. Hence, real appreciation is translated by the increase in the price of the domestic good. Our simulations show that the price of the domestic good increased by about 3.6 percent as a result of the increase in foreign transfers.
} 
domestic good. The decline of the export sector also explains the observed fall in intermediate imports.

Whether an increase in foreign transfers causes real appreciation or not, depends on the value of the elasticity of substitution between the home good and imports. Devarajan, Lewis and Robinson (1990) explain that when the elasticity of import substitution is close to infinity the domestic good and imports are perfect substitutes. Thus, there is no need to increase local production. All extra foreign exchange will finance imports and there will be no change in the amount of domestic good consumed. If the elasticity of substitution were zero, the domestic good and imports would be perfect complements and more of both would be consumed in the new equilibrium. All other cases fall within these two limiting ones.

As far as the welfare effects are concerned, we note that aggregate consumption increased by almost 10 percent. The underlying distributional mechanisms assign 80 percent of the transfer to urban households. This explains why urban consumption increases by about 15 percent while rural consumption increases only by 1.5 percent. Overall poverty incidence declines by about 3.4 percent. The urban bias in redistribution of the foreign transfer causes urban poverty incidence to fall by about 17 percent. Rural poverty declines only by 1.3 percent.

Should the Dutch disease be a matter of policy concern? According to Corden (2002), if the underlying real appreciation happens suddenly or is likely to be reverse in due course, then policy-makers may wish to mitigate the adverse impact of real appreciation on the tradable sectors. In the context of a fixed exchange regime with an independent monetary policy, or in a regime of managed float, the government may try to sterilize the effects of foreign capital inflow on the supply of money. Fiscal contraction can also help in this situation. Benjamin, Devarajan and Weiner (1989) describe how Cameroon tried to mitigate the Dutch disease effects associated with the oil boom of the 1970s. The country has a fixed exchange rate and no independent monetary policy since it belongs to the CFA zone. In order to mitigate the undesirable effects of the oil boom, the government decided to save a large share of the oil revenues abroad and to use some 
of the windfall to increase the producer price of cash crops, and thus counteracting the adverse incentive effects induced by real appreciation.

\section{Deterioration of the Terms of Trade}

As noted by Devarajan, Lewis and Robinson (1990), the outcome of a deterioration of the terms of trade depends on the interaction between the income and substitution effects induced by the change in the terms of trade. This interaction is governed by the degree of substitutability between the home and import goods as indicated by the elasticity of substitution. In particular, an increase in the world price of imports lowers households' real income (income effect) and renders the home good more attractive relative to the foreign good (substitution effect). When the elasticity of substitution is less than one, the income effect dominates. An increase in the world price of imports would therefore lead to real depreciation as the demand for both imports and home goods falls. The real depreciation of the exchange rate causes resources to shift out of the domestic good sector into the production of more exports to pay for imports which have become more expensive.

When the elasticity of substitution is greater than one, as in the case presented here, the substitution effect dominates the income effect. The increased demand for the domestic good induces real appreciation of the exchange rate which leads to a contraction of the exports. Table 3.1 indicates that a 10 percent increase in the world price of final imports would lead to a 14.11 percent cut in final imports and a 5.5 percent decrease in exports. Intermediate imports fall by 5.33 percent while the production of the domestic good increases by 1.83 percent. The deterioration of the terms of trade causes consumption to fall both in the rural and urban areas. Poverty incidence increases by 2.6 percent in the rural area and 3.33 percent in the urban area. 


\subsection{Budgetary Policy}

Table 3.2 Efficiency and Poverty Implications of Budgetary Policy

\begin{tabular}{lrrrrrrrr}
\hline & Base & Exp3 & Exp2 & Exp1 & Reference & Exp4 & Exp5 & Exp6 \\
\hline Exports & 30.0 & 106.3 & 104.3 & 102.2 & 100.0 & 97.7 & 95.3 & 92.8 \\
Domestic Good & 75.0 & 97.9 & 98.6 & 99.3 & 100.0 & 100.8 & 101.6 & 102.4 \\
Final Imports & 27.0 & 106.7 & 104.5 & 102.3 & 100.0 & 97.6 & 95.1 & 92.5 \\
Intermediate Imports & 3.0 & 103.0 & 102.1 & 101.1 & 100.0 & 98.8 & 97.4 & 96.1 \\
Total Consumption & 100.0 & 99.9 & 100.0 & 100.0 & 100.0 & 100.0 & 100.0 & 99.9 \\
Rural Consumption & 40.0 & 107.7 & 107.4 & 107.1 & 106.7 & 106.3 & 105.8 & 105.4 \\
Urban consumption & 60.0 & 94.8 & 95.0 & 95.3 & 95.6 & 95.8 & 96.1 & 96.3 \\
Total Poverty Incidence & 59.2 & 97.1 & 97.2 & 97.3 & 97.5 & 97.6 & 97.8 & 98.0 \\
Rural Poverty Incidence & 78.3 & 94.4 & 94.7 & 94.9 & 95.2 & 95.5 & 95.8 & 96.1 \\
Urban Poverty Incidence & 30.5 & 107.6 & 107.2 & 106.8 & 106.4 & 106.0 & 105.6 & 105.3 \\
Overall Poverty Gap & 29.7 & 95.3 & 95.4 & 95.6 & 95.8 & 96.1 & 96.3 & 96.6 \\
Rural Poverty Gap & 38.7 & 92.5 & 92.8 & 93.1 & 93.5 & 93.9 & 94.3 & 94.7 \\
Urban Poverty Gap & 16.3 & 104.9 & 104.7 & 104.4 & 104.1 & 103.9 & 103.6 & 103.4 \\
\hline
\end{tabular}

Source: Author's calculations

This section replicates and extends the policy experiments reported in Devarajan, Lewis and Robinson (1990) ${ }^{7}$. Our extension concerns the disaggregation of the household account, the redistributive assumptions associated with public expenditure, and the computation of the poverty implications. Three indirect tax instruments are available to the government: tariffs on final and intermediate goods and an indirect tax on domestic sales. The base data in the SAM represent a solution of the model with no government intervention i.e. all taxes set equal to zero.

The results in table 3.2 involve seven experiments and are presented in the form of ratios (in percentage) of the value taken by a variable in a given scenario to the baseline value of the same variable. The reference experiment sets the tax on domestic sales at 15.4 percent and both tariffs at 12.5 percent. Considering the pattern of production and imports, the results show that there is no change from the base case where there is no government intervention. In terms of efficiency, this configuration of taxes is optimal in the sense that it does not distort private sector decisions. The redistributive

\footnotetext{
${ }^{7}$ These authors framed the issue in terms of optimal taxation and solved the model as a mathematical programming problem using GAMS (General Algebraic Modeling System). Our numerical implementation uses EViews 5.1 which cannot solve the programming problem. We simply took the reported levels of different taxes and solved the model as a system of non-linear equations to find the efficiency and poverty implications of these policies. The interested reader can request the computer code we used to generate the results.
} 
policy causes the overall poverty incidence to decline by about 2.5 percent. This is mainly due to a 5 percent decrease in rural poverty. Urban poverty increases by more than 6 percent.

The second block of experiments comprises cases 1 through 3. In these cases, the sales tax rate is successively set at 5, 10 and 15 percent above the reference value of 15.4 percent. The corresponding values for the tariff rate on the final imports are (10.3, 8.2, 6.2). The associated values for the tariff on intermediate imports are (18.3, 24.2, 30.5). In all these cases, the production of exports increases, that of the domestic good declines with respect to the reference simulation, and imports increase. While the pattern of change in poverty incidence is similar to that observed in the reference case, rural poverty reduction is a bit higher than in the reference case, so is the increase in urban poverty.

The third group of experiments (cases 4 through 6) is symmetrical to the first. The sales tax is progressively set to 5, 10 and 15 percent below the reference value. The values for the tariff on final imports are $(14.8,17.3,20.0)$, and those for the tariff on intermediate imports are $(7.0,1.6,-3.6)$. In all these cases, the production of exports and all imports fall, while the production of the domestic good increases. Now rural poverty reduction is less than what it is in the reference run, similarly for the increase in urban poverty.

It is interesting to note that, for all experiments, the aggregate welfare effects (as measured by changes in total consumption) are negligible. However the structural and distributional impacts are significant. These are the outcomes that will drive the political economy of the process of policy-making. Focusing on efficiency considerations alone, Devarajan, Lewis and Robinson (1990) note that it is optimal to adopt a uniform tariff structure only when other indirect taxes are set optimally. However, the structural effects and the induced distributional impact determine what policy configuration actually gets implemented.

\section{Concluding Remarks}

The poverty and distributional impact of macroeconomic shocks and policies can be analyzed in terms of induced change in the mean and in relative inequality. The Lorenz curve provides an integrative framework for the simulation of the size distribution 
of economic welfare and the associated poverty and inequality measures. This framework has often been used alone to simulate the poverty implications of macroeconomic events without an explicit macroeconomic model. This paper shows how to extend this approach by embedding it in a general equilibrium model.

The resulting simulation model is consistent with the extended representative household approach (ERH) to the analysis of poverty and distributional issues within a general equilibrium framework. Our particular illustration of this approach is based on a stylized extension of the Generalized Salter-Swan model of international trade. This choice allows one to consider the implications of exogenous shocks such as changes in foreign transfers and in terms of trade, as well as the impact of budgetary policy. This stylized model may be interpreted as a small open developing country exporting a primary agricultural commodity produced by smallholders using low-tech methods of production. The size distribution in both the rural and the urban sector is modeled by the general quadratic model. The mean of the distribution is the key linking variable between the general equilibrium and the Lorenz model.

A key lesson emerging from all the experiments discussed in the paper stems from the fact that, while aggregate welfare and poverty effects may be negligible, the structural and distributional impacts are significant. The latter drive the political economy of policy-making, and point to the need for an analytical framework that accounts for both the structural richness of the economy and the heterogeneity of the stakeholders. 


\section{References}

Armington, Paul S. 1969. A Theory of Demand for Products Distinguished by Place of Production. IMF Staff Papers Vol. 16, pp. 159 - 176. Washington, D.C.: The international Monetary Fund.

Bandara, Jayatilleke S. 1991. Computable General Equilibrium Models for Development Policy Analysis. Journal of Economic Surveys, Vol. 5, No.1 : 3-69.

Bénassy Jean-Pascal. 2002. The Macroeconomics of Imperfect Competition and Nonclearing Markets: A Dynamic General Equilibrium Approach. Cambridge (Massachusetts): The MIT Press

Benjamin, Nancy C. and Devarajan Shantayanan. 1985. Oil Revenues and Economic Policy in Cameroon: Results from a Computable General Equilibrium Model. World Bank Staff Working Papers No. 745. Washington, D.C.: The World Bank. and Shantayanan Devarajan and Robert J. Weiner. 1989. The

"Dutch" Disease in a Developing Country : Oil reserves in Cameroon. Journal of Development Economics. Vol. 30: 71 - 92.

Blejer Mario I. and Chu Ke-Young. 1989. Introduction. In Mario I Blejer and Ke-Young Chu (eds), "Fiscal Policy, Stabilization and Growth in Developing Countries. Washington D.C: International Monetary Fund (IMF).

Bourguignon, François, Robilliard, Anne-Sophie, and Robinson, Sherman. 2003. Representative versus Real Households in the Macro-economic Modeling of Inequality. Working Paper No. 2003-05. Paris: Département et Laboratoire d’Economie Théorique et Appliquée (DELTA).

Cooper Richard N. 1992. Economic Stabilization and Debt in Developing Countries. Cambridge (Massachusetts): The MIT Press.

Corden W. Max. 2002. Too Sensational: On the Choice of Exchange Rate Regimes. Cambridge (Massachusetts): The MIT Press.

Datt, Gaurav. 1998. Computational Tools for Poverty Measurement and Analysis. Washington D.C.: International Food Policy Research Institute (IFPRI) Discussion Paper No.50 (Food Consumption and Nutrition Division). 
Datt, Gaurav. 1992. Computational Tools for Poverty Measurement and Analysis. Washington D.C.: The World Bank (mimeo)

Datt, Gaurav and Ravallion, Martin. 1992. "Growth and Redistribution Components of Changes in Poverty Measures: A Decomposition with Applications to Brazil and India in the 1980s.” Journal of Development Economics 38, 275-95.

Decaluwé, Bernard, Jean-Christophe Dumont, and Luc Savard. 1999. "Measuring Poverty and Inequality in a Computable General Equilibrium Model.” CREFA Working Paper 99-20, Laval University, Department of Economics, Research Center in Applied Economics and Finance, Montreal.

de Melo, Jaime and Robinson, Sherman. 1980. The Impact of Trade Policies on Income Distribution in a Planning Model for Colombia. Journal of Policy Modeling 2, No. 1: $81-100$.

Dervis, Kemal, Jaime de Melo, and Sherman Robinson. 1982. General Equilibrium Models for Development Policy. Washington, DC: World Bank.

Devarajan, Shantayanan, Jeffrey D. Lewis, and Sherman Robinson. 1990. Policy Lessons From Two-sector Models. Journal of Policy Modeling 12 (4): 625-657.

Devarajan, Shantayanan and Jeffrey D. Lewis. 1989. Structural Adjustment and Economic Reform in Indonesia : Model-based Policies vs Rules-of-Thumb. In Dwight H. Perkins and Michael Roemer (eds) . "Reforming Economic Systems in Developing Countries”. Cambridge, M.A.: Harvard University.

Dinwiddy, C.L. and F.J. Teal. 1988. The Two-Sector General Equilibrium Model: A new Approach. Oxford: Philip Allan.

Drazen Allan. 2000. Political Economy in Macroeconomics. Princeton: Princeton University Press.

Essama-Nssah B. 2004. Building and Running General Equilibrium Models in EViews. Policy Research Working Paper 3197. Washington, D.C.: The World Bank.

Foster, J., J. Greer, and E. Thorbecke. 1984. “A Class of Decomposable Poverty Measures.” Econometrica 52 (3): 761-66.

Johnson, Norman L., Kotz, Samuel, and Balakrishnan, N. 1995. Continuous Univariate Distributions. Volume 2. New York: John Wiley \& Sons.

Lambert, Peter J. 2001. The Distribution and Redistribution of Income. Manchester: Manchester University Press. 
Ravallion, Martin, and Michael Lokshin. 2004. "Gainers and Losers from Trade Reform in Morocco.” Policy Research Working Paper 3368, World Bank, Washington, DC.

Ravallion, Martin and Datt, Gaurav. 1992. Growth and Redistribution Components of Changes in Poverty Measures: A Decomposition with an Application to Brazil and India in the 1980s. Journal of Development Economics, 38: 275-295.

Robinson, Sherman, and Hans Löfgren. 2005. "Macro Models and Poverty Analysis: Theoretical Tensions and Empirical Practice.” Development Policy Review 23 (3): 267-83.

Robinson, Sherman, and Laura D’Andrea Tyson. 1984. "Modeling Structural Adjustment: Micro and Macro Elements in a General Equilibrium Framework.” In Applied General Equilibrium Analysis, ed. Herbert E. Scarf and John B. Shoven, Chapter 6. Cambridge, UK: Cambridge University Press.

United Nations. 2000. United Nations Millennium Declaration. Resolution 55/2 Adopted by the General Assembly (September 18, 2000). New York: United Nations. 